5. Anterior colpotomy and sling through retrograde posterior colpotomy to ensure clear margins and complete detachment of cervix, vaginal cuff, paracolpium and parametrium from distal vagina

6. Insertion of H8 Hagars dilator into uterine cavity through cervical os

7. En bloc retrograde resection of cervix, vaginal cuff, paracolpium and parametrium at level of isthmus

8. Insertion of cervical cerclage around distal uterus and dilator using \#1 continuous prolene suture

9. Replacement of Hagars dilator with Foleys catheter subsequently removed 48 hours post-operatively

10. Formation of neo-cervix using \#1 vicryl interrupted suture between distal uterine body and proximal vaginal cuff Conclusion* We highlight the importance of a systematic approach to this challenging technique, acknowledging specialist anatomical knowledge and surgical skills. We present a stepwise procedure, achieving en block radical excision with fertility sparing preservation of ascending uterine artery branch, round and infundibulopelvic ligaments.

\section{IMPACT OF CERVICAL CANCER SCREENING ON DIAGNOSIS AND MORTALITY OF CERVICAL CANCER IN OSAKIDETZA}

${ }^{1} \mathrm{C}$ Blasco de Imaz Alonso*, ${ }^{2} \mathrm{~S}$ Huerta Martin, ${ }^{3} \mathrm{D}$ Del Valle, ${ }^{2} \mathrm{~A}$ Lekuona Artola, ${ }^{2 ; 4} \mathrm{R}$ Ruiz, ${ }^{1} \mathrm{P}$ Cobas, ${ }^{2} \mathrm{AP}$ Gurría De la Torre, ${ }^{3} \mathrm{M}$ Gorostidi, ${ }^{5}$ Jaunarena, ${ }^{3} \mathrm{~J}$ Céspedes Manterola, ${ }^{3}$ E Arenaza Lamo, ${ }^{3}$ A Dávila Expósito, ${ }^{6}$ A Arrainza Armendariz. ${ }^{120014}$, Spain; ${ }^{2} 20014$, Spain; ${ }^{3}$ Donostia, Spain; ${ }^{4} 20014 ;{ }^{5}$ Donostia, Spain; ${ }^{6}$

\subsection{6/ijgc-2021-ESGO.89}

Introduction/Background* Sistematic cervical cancer screening covering $70 \%$ of population has shown a decrease in the incidence and mortality in northen Europe of over $80 \%$.

In the Basque Country, we implemented cervical screening in 1985. Inicially, unorganized opportunistic screening took place, moving on to an organized opportunistic screening. Since 2018 organized population screening has been carried out which will be completed in 2023 .

Methodology Cervical cancer cases detected between 2018 and 2020 have been analysed, both inside and outside the screening. We centered our analysis on the stages of cancer at diagnosis and ulterior prognosis

Result(s)* The total of cancers diagnosed was 294: 92 in 2018, 92 in 2019 and 110 in 2020.

The mean age at diagnosis was 54 years.

Regarding histology, we found squamous carcinoma in $71.2 \%$ of the cases, adenocarcinoma in $27.2 \%$, endometrioid in $1.1 \%$ and clear cervical cell carcinoma in $0.5 \%$.

Within our programme, $25.5 \%$ of the subjets were directly diagnosed after the performance of a VPH cytology and $10.33 \%$ during the follow up,

Outside screening, 51,63\% were diagnosed after symptoms, $2,72 \%$ due to findings in imaging test and $9.78 \%$ of cases were detected in private clinics.

$68.18 \%$ of cancers diagnosed by the programme were initial stages. However, only $13.95 \%$ of those diagnosed outside the screening were in an initial stage.

Taking into consideration all the cases, $37.5 \%$ of cases did not do any screening test before, $27.2 \%$ did, $26.1 \%$ did a correct it incorrectly and $9.2 \%$ did the follow-up in private clinics.
Finally, concerning mortality up to January $2021,4.16 \%$ of women diagnosed in initial stages and $22.03 \%$ diagnosed in advance stages died $(10.34 \%$ and $89.66 \%$ of total deaths, respectively).

Conclusion* FIGO staging is the main prognostic factor, $89.66 \%$ of deaths were diagnosed in an advanced stage. According to our study, $68.18 \%$ of the cancers diagnosed inside the screening were in initial stages, comparing to only a $13.95 \%$ outside the programme.

$64.7 \%$ of women with cervical cancer had not previously performed a screening test or have it in an inappropriate way. The establishment of a sistematic cervical cancer screening programme can reduce global mortality due to this disease.

\section{ONCOLOGICAL OUTCOMES OF LAPAROSCOPIC NERVE- SPARING RADICAL HYSTERECTOMY WITHOUT UTERINE MANIPULATOR}

${ }^{1}$ D Zygouris*, 'A Gkoutzioulis, ${ }^{2} S$ Papadimitriou, ${ }^{1}$ E Stergiannakou, ${ }^{1} \mathrm{~A}$ Kavallaris. ${ }^{1}$ St. Luke's hospital, Department of Gynecologic Oncology, Thessaloniki, Greece; ${ }^{2}$ University Hospital of Ioannina, Department of Blood Transfusion, Ioannina, Greece

\subsection{6/ijgc-2021-ESG0.90}

Introduction/Background* The aim of this study is to evaluate surgical data and oncological outcome of laparoscopic nervesparing radical hysterectomy without uterine manipulator for cervical cancer stage IB, over the last 10 years.

Methodology This retrospective study includes 39 patients with cervical cancer Figo stage (2009) IB who underwent laparoscopic nerve-sparing radical hysterectomy without using any kind of uterine manipulator. Patients were eligible if they had squamous cell carcinoma, adenocarcinoma, or adeno-squamous carcinoma, and no para-aortic lymph node involvement by imaging or after frozen section. The median value and range were assessed for operative outcomes and relapse rate and disease-free survival rate were evaluated using the Kaplan-Meier method.

Result(s)* In the study, 39 patients were included and among them 32 women were stage IB1 (21 cases with tumor size 2$4 \mathrm{~cm}$ ) and 7 women stage IB2 (Figo stage 2009). The median age of patients was 49.6 years (range 31-68) and median body mass index (B.M.I) was $26.1 \mathrm{~kg} / \mathrm{m} 2$ (range 19$33.5 \mathrm{~kg} / \mathrm{m} 2$ ). The average operating time was $226 \mathrm{~min}$ (range 147-310 $\mathrm{min}$ ) and median hospital stay was 2.6 days (range 2-7 days). Approximate blood loss was $184 \mathrm{ml}$ (range 120$300 \mathrm{ml}$ ). After a median follow-up of 48 months, we had 2 recurrences out of 32 cases and no death. Especially for patients with Figo stage (2009) IB1, the recurrence rate was $3.1 \%(1 / 32)$. The 3-year PFS was $93.7 \%$ and the number at risk $23(71.8 \%)$ and especially for the IB1 stage (2009) women, the 3-year PFS was $96.1 \%$ and the number at risk $21(77.7 \%)$. The 3-year OS was $100 \%$ with no. at risk $71.8 \%$.

Conclusion* Laparoscopic nerve-sparing radical hysterectomy without uterine manipulator is feasible and safe surgical procedure for cervical cancer with acceptable surgical and oncological outcomes in the hands of well-trained and experienced laparoscopic surgeons. Our retrospective study reveals better oncological outcome compared to other studies on the minimally invasive approach, where uterine manipulator was routinely used and no vaginal sealing of the tumor was made. 